\title{
A propósito del libro Bolero y Tango: dos sobrevivientes de Luis Enrique García*
}

M.M. Fernando de Jesús Serrano Arias fserranoa@capomo.uson.mx

Departamento de Bellas Artes

E n el imaginario colectivo, cuando un extranjero piensa en la música de México, lo primero que se le ocurre es el Mariachi. Como si, de península a península todos fuéramos charros y, tristemente, estuviéramos siempre sentados bajo un sombrero gigante, enfundados en un zarape y recargados en un sahuaro. ¿A quién se le habrá ocurrido que uno se puede recargar en una planta atestada de espinas?

A la Argentina le ocurre lo que a México. Pareciera que toda su música es tango. Como, si por generación espontánea, del arrabal surgiera una música sin pasado pero, con un gran futuro y, nos olvidamos de milongas, zambas, vidalitas, gatos, cuecas, etc.

En el libro, Luis Enrique nos lleva, en un principio y tomando el bolero como pretexto, a través de la historia de una parte de la música popular en México; pero no se queda allí nos habla de sus antecedentes musicales, de su recepción y su influencia fuera de México. Así, pasamos del bolero cubano al bambuco colombiano y, de allí, a la trova Yucateca para adentrarnos al bolero en México.

Narra el trasiego de los diferentes géneros y, a pesar de las barreras geográficas, se adoptan, se adaptan y toman carta de naturalización en México para, desde aquí, retomar rumbo a toda América. Incluye la intromisión de la radio y la televisión "para bien y para mal", la llegada del Rock, esa música "extranjera subversiva y alienizante" y al resurgimiento de los géneros.

Realiza el recorrido presentándonos a personajes unos más conocidos que otros y nos permite conocer y reconocer cosas. Así, supe de Genaro Salinas, tenor mexicano que murió -o lo mataron- joven y que gracias a Internet pude escuchar y coincidir con las apreciaciones del autor. Reconocer yerros en mi conocimiento sobre el género. Corregir, por ejemplo, que el autor de la pieza "As de corazones" es Luis Arcaráz y no Agustín Lara, como supuse durante mucho tiempo o que "Perfume de gardenias" es boricua y no cubana. O descubrir que, cómicos mexicanos de la época dorada del cine, aparecen cantando, tal es el caso de Fernando Soto "mantequilla" y "El Chino" Herrera. $\mathrm{O}$, aprovechar la narrativa cronológica de las obras mencionadas y aprovechar de nuevo las ventajas de la tecnología para dar un seguimiento auditivo a los tangos y, descubrir en ello, el desarrollo de un género, a través de sus creadores e intérpretes.

* García, L. E. (2017). Bolero y Tango: dos sobrevivientes. México: Universidad de Sonora. 
Luis Enrique nos describe, también, el recorrido que hace el tango; su inaceptable condición de paria musical por su malevo y arrabalero origen que, tras su asentamiento parisino, regresa con la frente en alto y es bien recibido por la buena gente porteña.

No puedo evitar hacer notar la similitud entre una música nacional y el tango, en esta aceptación de las clases más favorecidas, como señala Luis Enrique. Es decir, el tango no es aceptado por la "buena sociedad" sino hasta que ha sido aprobado allende sus fronteras. Algo similar pasó en el México decimonónico cuando, lograda la independencia, músicos extranjeros que, con el afán de congraciarse con el público Mexicano en sus conciertos, hacen arreglos de "sonecitos del país". Esto bastó para que nuestros músicos -en la segunda mitad del siglo XIX- realizaran sus propios arreglos de "música mexicana", no exentos de virtuosismo en algunos casos. Una pregunta surge de todo esto: ¿es condición necesaria vernos en los ojos del extranjero para apreciar lo propio?

El libro señala también el antecedente común de los dos, la habanera cubana. Podemos notar la influencia de la música traída del África en ambos casos y notar la resiliencia de estos sobrevivientes a quienes, a falta de una definición específica, -ritmo, forma, género- a decir del mismo Luis Enrique, los hemos dotado de una especie de vida propia.

¿Cómo podemos definir qué es lo que hace al bolero, bolero y al tango, tango? ¿Es el ritmo, el compás, la melodía, la letra? ¿Es un ritmo, una forma musical o un género? Bajo estas preguntas tomamos los ejemplo expuestos en el libro. Los casos de "Dónde estás corazón”, bolero que viaja de México a Argentina y en el vuelo se convierte en tango. O el de "Júrame", compuesto como tango y que se interpreta como bolero. Y si esto nos cuesta trabajo, tratemos de distinguir, los que no somos originarios de Argentina, una milonga de un tango. Y los de casa, definamos lo que diferencia a un bolero de un bolero ranchero. ¿Si lo toca un trío es urbano y si lo ejecuta un mariachi es ranchero? De ser esto así, expongamos el emblemático caso, también señalado en el texto, de la interpretación que hace Javier Solís de "Sombras nada más", que a fin de cuentas es un tango interpretado por un mariachi a ritmo de bolero.

Podríamos pensar también, la relación entre el texto y las músicas. El tango está ligado inexorablemente al "lunfardo". Que muchas de sus palabras tienen su propia creación y significado y en otras, palabras de uso común en otras regiones hispanoparlantes tiene uno distinto. Vayan dos palabras a guisa de ejemplo: Bulín, que se define como una habitación no de muy buenas condiciones y Papa, que se refiere, por lo general, a una mujer bonita. Así, si escuchamos en un tango la expresión "la más papa milonguera" no debemos pensar que es una verdura que le gusta la milonga, sino una bella mujer.

De igual manera pudiéramos pensarlo en la música mexicana, particularmente en la que se señala como ranchera aunque no en el mismo grado. Expresiones como "chinita por tus quereres", no hace referencia a una mujer asiática, sino a una "forma cariñosa" de referirse a la dama pretendida. 
Al final de la sección dedicada a cada uno de estos "sobrevivientes", el autor nos da señales de la renovada vida que han tenido. Cada uno ha visto resurgir el interés por su música. Actualizados no sólo en instrumentación u orquestación en algunos casos, como son las presentaciones orquestadas de los boleros con cantantes de actualidad o la inclusión de obras de estos géneros dentro de la llamada "música de concierto", lo cierto es que también se presenta una restitución del pasado, un dejo nostálgico que se mantiene, las orquestas típicas criollas que, mantienen una instrumentación "original" (así, entre comillas) o los nuevos tríos que tratan de mantener esa forma, también "original" (entre comillas) de la tradición bolerística de, una época dorada del estilo.

Sin embargo, el caso del tango tiene otras implicaciones, la llegada de Astor Piazzola le da a esta música Argentina un nuevo aire que parte de la tradición urbana y se mete a fondo en la música de concierto. No ha ocurrido así con el bolero, no hay composiciones nuevas en este género que hayan trascendido ese umbral, como si pasó con el danzón, tal vez, como señalaba Luis Enrique en una conversación previa que tuvimos, el arraigo a la letra no le ha permitido al bolero subirse a esta escena. Por otro lado, el tango se ha convertido en carta de presentación de la Argentina urbana y, como ha sucedido con otras danzas de salón, la estilización del baile le ha ganado un lugar en otros espacios que le ha dado otra vitalidad.

Ese apego romántico propio del bolero, que durante muchas épocas en México sirvió para llevar serenatas, valor que se ha ido perdiendo en parte por las nuevas disposiciones administrativas, en parte por la desconfianza, en parte por la pérdida de esa idea romántica en sí, donde frases a veces poéticas, a veces melosas, permitían decir cosas a través de la música a la persona que nos robaba el sueño o regalarle a las mamás canciones en su día. Sin embargo, las nuevas poéticas urbanas han desviado estos textos. Ritmos, también con bases africanas han ganado terreno, desintegrando la parte romántica y acrecentando la parte sensual y, en muchas ocasiones machista de la visión masculina. Así, si en otros tiempos le habríamos cantado "aviva la llama de mi fuego", en estos tiempos cantaríamos "dame más gasolina, quiero más gasolina".

Fecha de presentación

24 de marzo de 2017

Hermosillo, Sonora. México 